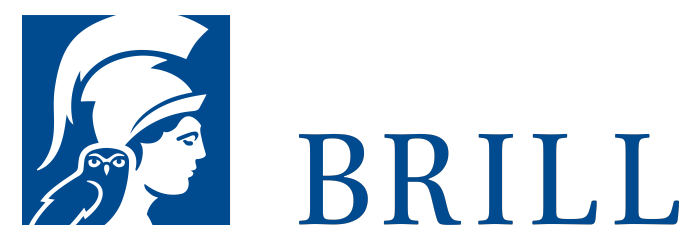

\title{
Minimalistische Poetik
}

Zur Ausdifferenzierung des Aufbausystemenin der

Romanliteratur der frühen DDR

Author: Matthias Aumüller

Das Hauptziel der Studie besteht in der

literaturwissenschaftlichen Aufarbeitung eines für die DDR-

Literatur grundlegenden Korpus: der Aufbauromane. In

Auseinandersetzung mit sowjetischen Vorläufern werden die

für das Korpus spezifischen Eigenschaften herausgearbeitet.

Textbezogene Einzeluntersuchungen und Werkanalysen machen deutlich, dass das auf den ersten Blick homogen wirkende Korpus in seinen einzelnen Ausprägungen vielfältige Unterschiede aufweist. Ein gestuftes Modell der Variation des Aufbausystems ermöglicht die systematische Beschreibung der Gemeinsamkeiten und Unterschiede der Mitglieder des Korpus sowie die Abgrenzung von anderen Korpora. Auf diese Weise können die Aufbauromane mit literaturgeschichtlichen älteren und jüngeren Werkgruppen verglichen und Kontinuitäten und Diskontinuitäten der literaturgeschichtlichen Entwicklung von der frühen Sowjetunion und Weimarer Republik bis zur DDRLiteratur der 6oer Jahre erfasst werden. Im Ergebnis zeigt sich, dass die Aufbauromane einer Poetik gehorchen, die insofern minimalistisch ist, als sie ihre literarische Bedeutung ausschließlich auf der Basis des Systems beziehen, zu dem sie qua Aufbauhandlung gehören.

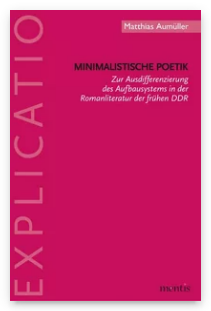

Pages: 391

Seiten

Language:

German

Subjects:

German,

Literature and

Cultural Studies

Publisher: Brill |

mentis

Series:

Explicatio

E-Book (PDF)

Released online:

12 Mar 2015

ISBN: 978-3-

89785-129-O

List price

Paperback

Publication date:

12 Mar 2015

ISBN: 978-3-

89785-122-1

List price 
For more information see brill.com

Order information: Order online at brill.com +44330 333 0049 | customerservices@brill.com Submission information: brill.com/authors

Titles published by Brill | Fink, Brill | mentis or Brill | Schöningh: +49(o)715413279216| brill@brocom.de 